\title{
Análise cartográfica da concentração do cultivo de mandioca no estado do Pará, Amazônia brasileira
}

\section{Cartographic analysis of concentration and geography of cassava in Pará State, Brazilian Amazon}

Luiz Henrique Almeida Gusmão* Alfredo Kingo Oyama Homma**

Orlando dos Santos Watrin**

\begin{abstract}
Resumo:
A representação cartográfica de fenômenos é muito relevante no discurso geográfico, pois o mapa é um instrumento de pesquisa que possibilita novas descobertas, revela padrões, formas, relações e dissimetrias no espaço. Neste trabalho, o software Philcarto foi avaliado como ferramenta de apoio na representação de dados sobre área plantada e produção da cultura da mandioca no Estado do Pará. Para isto, dados estatísticos relativos a esta cultura foram tratados de modo a serem representados sob a forma cartográfica mais adequada. Foi verificado que Nordeste Paraense e Baixo Amazonas foram as principais regiões de plantação e produção de mandioca no Estado do Pará, assim como também registraram as maiores expansões dessa atividade no período considerado. O uso de mapas temáticos foi importante na representação de distribuição, desigualdade e evolução dos componentes da atividade mandioqueira no Estado do Pará.
\end{abstract}

\begin{abstract}
:
The cartographic representation is very relevant in a geographical discourse, since the map is a research tool that enables new discoveries, reveals patterns, shapes, relationships and asymmetries in space. In this work, the Philcarto software was evaluated as a supporting tool in the representation of data on planted and production of cassava in the regions of Pará, Brazil. For this, statistical data on this culture were treated so as to be represented in the most appropriate cartographic manner. It was found that the Nordeste Paraense and the Baixo Amazonas regions are the main areas of cultivation and production of cassava, as well as recorded also the largest expansions of this activity in the period considered. The use of thematic maps was important for the representation of distribution, unbalanced and evolution of the cassava agricultural activities in the study area.
\end{abstract}

* Bolsista CNPq vinculado ao Lab. de Sensoriamento Remoto da Embrapa Amazônia Oriental (EMBRAPA)

** Pesquisador da EMBRAPA Amazônia Oriental
Palavras-chave:

Cartografia temática, Semiologia gráfica, Produção agrícola

Key-Words:

Thematic cartography, Graphic semiology, Agricultural production 


\section{INTRODUÇÃO}

A Cartografia Temática vem sendo largamente Aempregada nos estudos geográficos, principalmente com o objetivo de representar espacialmente qualquer ação, noção, objeto ou fenômeno, através da elaboração de mapas sobre temas variados, baseados principalmente na semiologia gráfica.

Conforme afirma Martinelli (2011), o mapa é por excelência parte do discurso geográfico e representa um instrumento poderoso na análise do espaço, podendo responder questões como: “o que?", “onde?”, "quando?", "quanto?", "em que ordem?" e algumas associações. A representação cartográfica de fenômenos tornou-se assim de grande importância, porque o mapa é um instrumento de pesquisa que possibilita novas descobertas, revela padrões, formas, relações e dissimetrias no espaço, reafirmando a sua potencialidade e o seu uso (GIRARDI, 2008). Assim, os produtos cartográficos, como mapas, devem obedecer a critérios estabelecidos na representação gráfica, no intuito de transmitir a informação de modo monossêmico, em um lapso mínimo de percepção, ou seja, sem ambiguidade (MARTINELLI, 2011).

Com o advento da revolução tecnológica dos anos 1980 foram dadas condições para o aparecimento de ferramentas computacionais valiosas para o desenvolvimento de estudos cartográficos em vários níveis de abordagem. É interessante avaliar as inovações trazidas pela informática e pelas novas concepções metodológicas da Geografia, em que os mapas temáticos são elementos primordiais para a pesquisa e análise dos fenômenos que ocorrem no espaço geográfico (MARTINELLI, 2011).

Dentre as ferramentas computacionais de apoio à Cartografia, aquelas baseadas em geotecnologias permitem a manipulação e a organização de grande volume de dados e informações espaciais e tabulares, possibilitando, inclusive, a obtenção de novas informações interpretativas a partir de modelos. Enfatiza-se, também, que tais ferramentas apresentam potencialidade para a transformação do dado espacial como instrumento no apoio à gestão e à tomada de decisão.

Segundo Waniez (2002), a utilização de ferramentas da informática em abordagens com dados estatísticos está diretamente ligada à cartomática. Nesse sentido, o Philcarto (PHILCARTO, 2014) representa um software livre de Cartografia Temática, contendo diversos mecanismos de mapeamento e análise espacial, sendo capaz de elaborar diversos mapas temáticos a partir do cruzamento de dados estatísticos com uma base cartográfica. Este software apresenta também ampla capacidade no armazenamento, manipulação e tratamento de dados estatísticos.

Em um contexto mais particular, a abordagem cartográfica é de suma relevância para a espacialização de componentes agrícolas, pois torna muito vantajosa a comunicação visual, compreensão e análise para os usuários. Isto é particularmente válido quando é destinada a órgãos públicos que têm por finalidade direcionar investimentos financeiros para fomentar o desenvolvimento socioeconômico e otimizar os sistemas de produção implantados no território.

A importância socioeconômica mundial da cultura da mandioca reside no fato que a mesma constitui a principal fonte de carboidratos para 800 milhões de pessoas, especialmente na América Latina, África e Ásia. Conforme Silva (2014), a mandioca é usada como alimento por largas faixas da população e consumida como farinha, amido, ou cozido, tendo ampla capacidade produtiva pela qualidade do seu amido que the permite alcançar novos mercados na indústria e na alimentação animal. Por sua vez, a relevância da mandioca para o Estado do Pará está associada à sua liderança em área plantada e produção no país (ano 2010), sendo uma cultura altamente demandante de mão de obra, com uma estimativa de 200 mil empregos gerados neste Estado (HOMMA, 2015). Uma parte da produção de farinha do Estado do Pará é destinada para exportação para os Estados do Amazonas, Amapá e para a Região Nordeste.

Considerando essas premissas, este trabalho tem por objetivo enfatizar a distribuição, a evolução e os contrastes regionais da produção de mandioca no Estado do Pará, ao longo do tempo e do espaço, a partir de mapas temáticos. Adicionalmente, busca-se analisar o desempenho de um software livre de cartografia temática (Philcarto), como ferramenta de apoio na representação de dados censitários.

\section{MATERIAL E MÉTODOS}

A área considerada para estudo corresponde ao Estado do Pará, localizado na Região Norte do Brasil, fazendo fronteira com os estados do Amapá, Maranhão, Tocantins, Mato Grosso e Amazonas. De acordo com IBGE (2015a), o Estado possui uma área de 1.247.689 $\mathrm{km} 2$, sendo formado por 22 microrregiões agrupadas em 6 mesorregiões (Figura 1). 


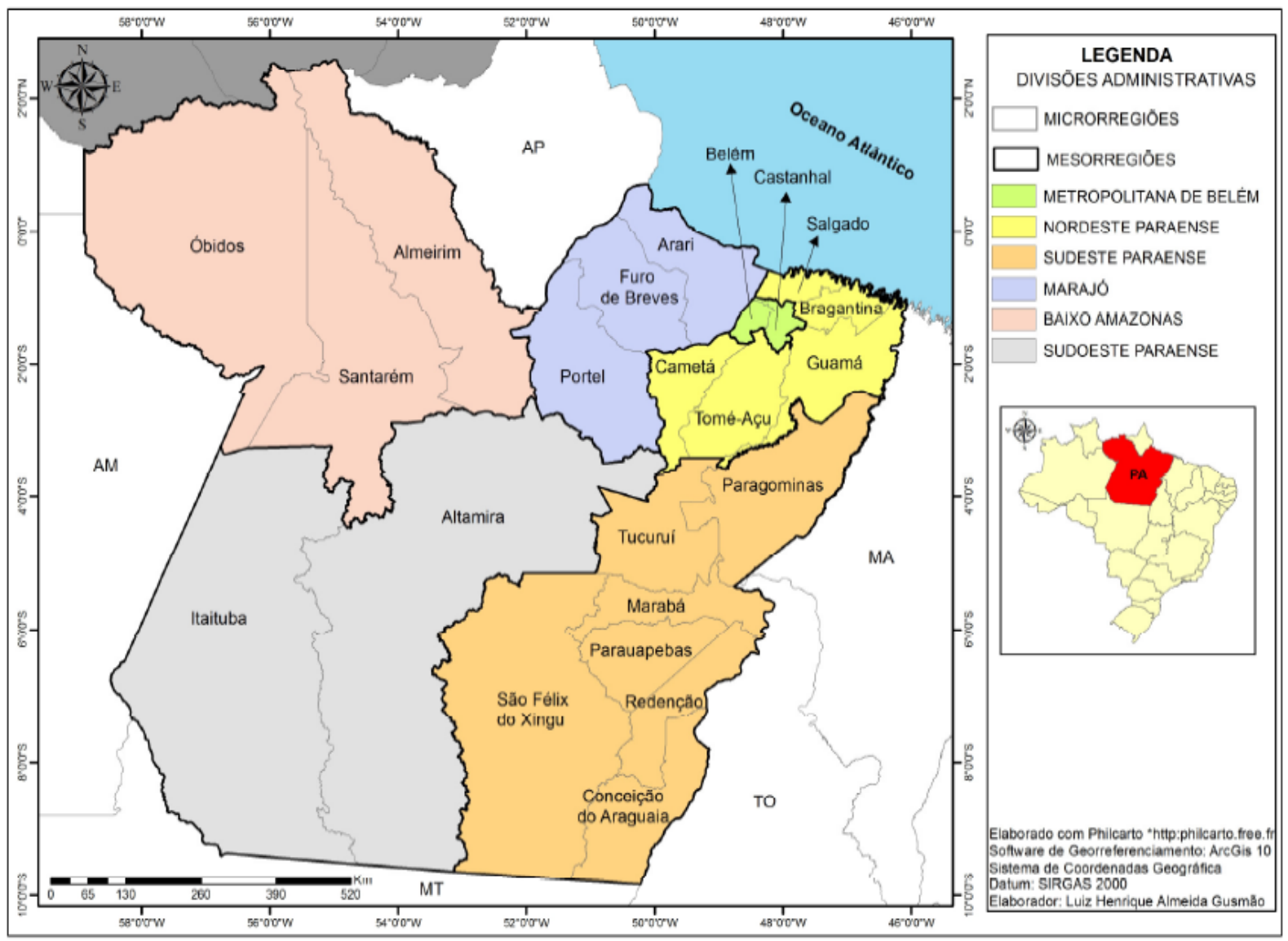

Figura 1 - Mesorregiões e Microrregiões do Estado do Pará. Fonte: Elaborado pelos autores

Com vista à obtenção de dados de área plantada e produção da cultura de mandioca para as 22 microrregiões do Estado do Pará nos anos de 1990, 1995, 2000, 2005 e 2010, foi realizado um levantamento no Sistema IBGE de Recuperação Automática - SIDRA (IBGE, 2015b). Os dados selecionados foram inseridos em uma planilha eletrônica (software Excel), sendo o arquivo gerado convertido para o formato "txt" (texto separado por tabulações), de modo a permitir a análise posterior no software Philcarto.

O software Excel também foi usado para a elaboração dos gráficos sobre a composição da área plantada e da produção de mandioca para as mesorregiões do Estado do Pará, com o intuito de facilitar a visualização e comparação do período de 1990 a 2010.

$\mathrm{O}$ arquivo espacial referente às microrregiões do Pará obtido a partir de IBGE (2013a) no formato "shp" (Shapefile) precisou ser convertido para o formato "Ai" (Adobe Illustrator), considerando o software Phildigit.
Tal procedimento foi necessário para que houvesse compatibilidade da base cartográfica com o banco de dados nos formatos específicos para a representação cartográfica no Philcarto. Após a fusão das bases, optou-se pelas formas de representação cartográfica consideradas mais adequadas às informações sobre a atividade mandioqueira, o que permitiu a elaboração de mapas temáticos, posteriormente analisados com base na semiologia gráfica proposta por Bertin (1986).

Pela necessidade de georreferenciar algumas figuras temáticas de interesse, tal procedimento foi realizado a partir do software ArcGis 10 (ESRI, 2015), considerando como sistema de coordenadas geográficas o datum SIRGAS 2000. Para a espacialização adequada dos dados, de modo a facilitar a interpretação e a consequente visualização instantânea, foram usados métodos de mapeamento para representar quantidades e taxas em mapas temáticos (MARTINELLI, 2011). Assim, foi emprega- 
do o método símbolo proporcional visando mostrar o tamanho da produção e área plantada, enquanto o uso do método coroplético teve como objetivo representar a variação percentual da produção e área plantada entre 1990 e 2015. Por fim, para representar a correlação entre área plantada e produção de mandioca após 25 anos, e as áreas prioritárias de investimento no agronegócio da mandioca, optou-se pelo método corocromático.

Os mapas de variação percentual da área plantada e da produção de mandioca na área de estudo consideraram uma divisão em cinco classes, de acordo com a variação observada entre estas variáveis de interesse: maior expansão (microrregião que teve a maior variação positiva das variáveis consideradas); alta expansão (microrregiões com crescimento da atividade acima de $50 \%$ ); baixa expansão (microrregiões com crescimento entre 1\% e 50\%); baixa redução (microrregiões com decréscimo entre - $1 \%$ e $-50 \%$ ) e alta redução (microrregiões com decréscimo acima de $-50 \%$ ), sendo os percentuais calculados a partir da fórmula:

Taxa de Variação Percentual $=[($ Valor recente Valor antigo)/ Valor antigo $* 100]$

\section{RESULTADOS E DISCUSSÃO}

O cultivo da mandioca sempre representou a lavoura com maior área plantada no Estado do Pará (IBGE, 2015a). Em 1990, a área plantada que era de 236.316 ha passou para 297.482 ha, em 2010, tendo assim uma expansão de 24,4\%. Entretanto, esta produção teve uma distribuição espacial bastante heterogênea entre as microrregiões que compõem o Estado, conforme pode ser observado na Figura 2.

Ainda segundo a Figura 2, percebe-se que as microrregiões com as maiores áreas plantadas de mandioca em 1990, variando entre 20.000 e 80.000 ha, estavam concentradas na mesorregião Nordeste Paraense e em parte do Sudeste Paraense, destacando-se as microrregiões: Paragominas, Guamá, Bragantina, Redenção e Altamira. Entretanto, durante o período entre os anos de 1995 e 2005 houve uma dinâmica espacial no Estado, que favoreceu o aumento gradual da área plantada em microrregiões onde o cultivo da mandioca é considerado mais tradicional, como Santarém, Óbidos, Tomé-Açu e Castanhal.

Por outro lado, é notável a estagnação ou redução da produção na maioria das microrregiões do Sudeste Paraense e Sudoeste Paraense, onde a produção de grãos e, sobretudo, a pecuária são atividades econômicas mais fortes, como observado em São Félix do Xingu, Paragominas, Redenção, Conceição do Araguaia, Altamira e Itaituba. Situação semelhante foi observada para a região do Marajó, onde a pecuária de bubalinos é de suma importância para a economia regional, bem como para a Mesorregião Metropolitana de Belém, onde as atividades comerciais, industriais e de serviços representam o pilar da economia.

A partir da dinâmica espacial ocorrida na variável área plantada, as microrregiões de Tomé-Açu, Guamá, Bragantina, Santarém e Óbidos, tornaram-se em 2010, as principais produtoras de mandioca no Estado do Pará. Dessa forma, tais microrregiões contribuíram para que as mesorregiões a elas associadas, Nordeste Paraense e Baixo Amazonas, apresentassem as áreas cultivadas mais extensas dessa cultura no Estado (Figura 3), assim como as maiores taxas de crescimento nos últimos 20 anos, em contraposição ao Sudeste Paraense, que teve a maior redução do Pará (Figura 4).

De forma a poder visualizar espacialmente as microrregiões que apresentaram maior expansão ou retração da área plantada de mandioca entre 1990 e 2010 no estado, foi elaborado um mapa temático coroplético com as variações percentuais observadas (Figura 5). Segundo este mapa, em 20 anos, nove microrregiões $(41 \%)$ apresentaram decréscimo na área plantada de mandioca, sendo cinco delas enquadradas como de baixa redução, ao passo que outras quatro foram avaliadas como de alta redução. Entre as que tiveram uma redução significativa, destacam-se as microrregiões: Paragominas (-80\%), Redenção (-80\%), São Félix do Xingu (-57\%) e Arari (-76\%), provavelmente devido à expansão da lavoura mecanizada de soja, milho e arroz, ao reflorestamento e à pecuária.

Ainda pela Figura 5, é perceptível a expansão da mandioca em mais da metade das microrregiões (59\%), sendo baixa em quatro e alta em nove, ou seja, a ampliação das áreas destinadas à plantação de mandioca ocorreu na maioria das microrregiões paraenses. Nesse contexto, a microrregião de Tomé-Açu teve uma expansão de 758,4\% em área plantada de mandioca, considerada a maior de todo o estado, seguida em ordem decrescente por Parauapebas (269\%), Óbidos (253\%), Santarém (249\%), Tucuruí (212\%) e Castanhal $(146 \%)$.

É importante salientar que as áreas destinadas ao cultivo de mandioca recrudesceram no Nordeste Paraense e Baixo Amazonas, regiões tradicionais de cultivo. Por outro lado, tais áreas apresentaram um comportamento bem variável nas mesorregiões do Marajó e do Sudeste Paraense, onde houve microrregiões com alta redução e alta expansão 

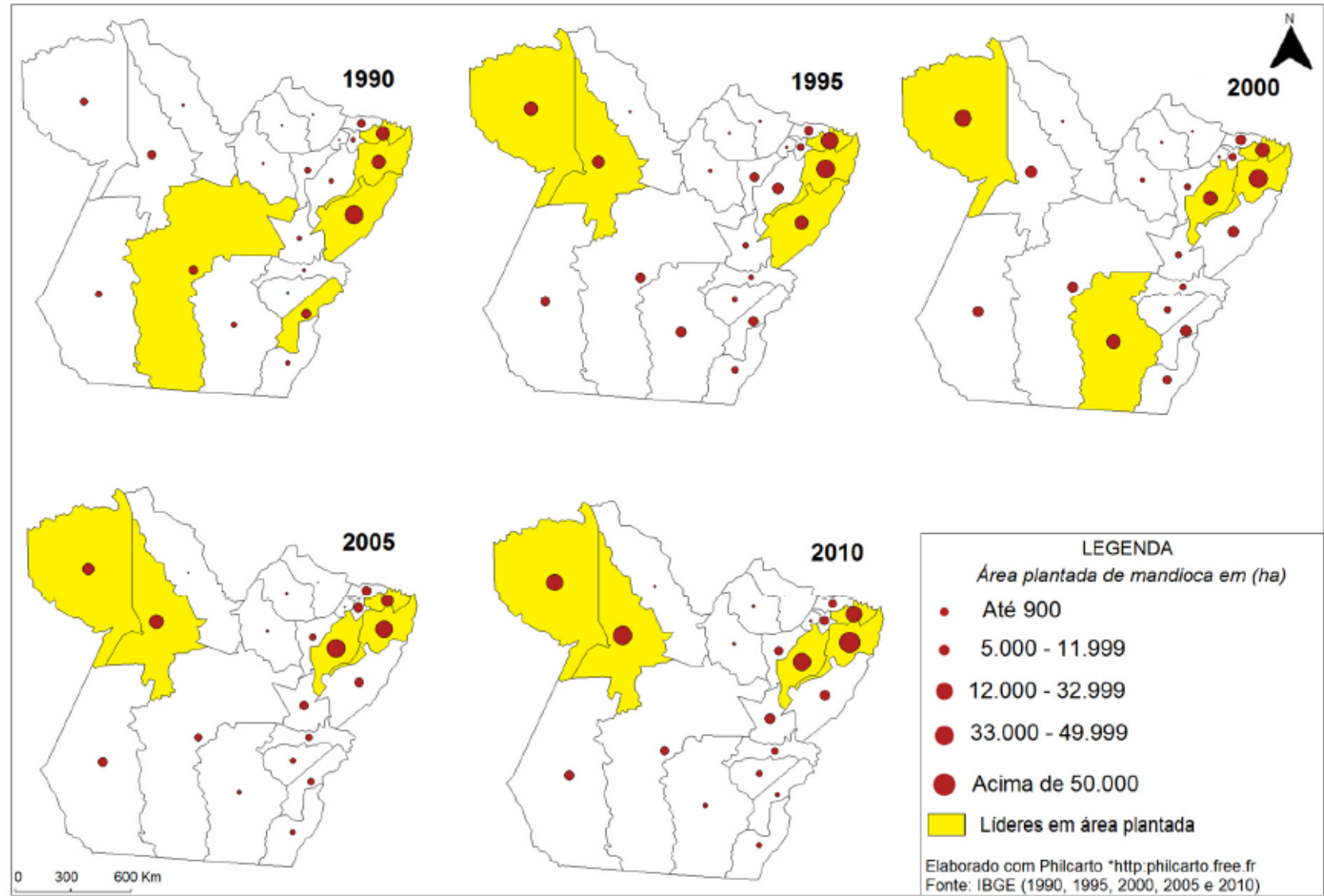

Figura 2 - Dinâmica da área plantada de mandioca em hectares nas microrregiões do Estado do Pará, nos anos de 1990, 1995, 2000, 2005 e 2010.

Fonte: Elaborado pelos autores a partir dos dados do IBGE

da área plantada, de forma simultânea.

Para Mattos e Cardoso (2013), é bem conhecido o papel social que desempenha a cultura da mandioca no Estado do Pará, pelo número representativo de famílias do meio rural que vivem da produção e do processamento da farinha. Entretanto, muitas vezes, não é destacada a importância econômica para os municípios produtores e para o Estado que hoje ocupa lugar de destaque como maior produtor nacional.

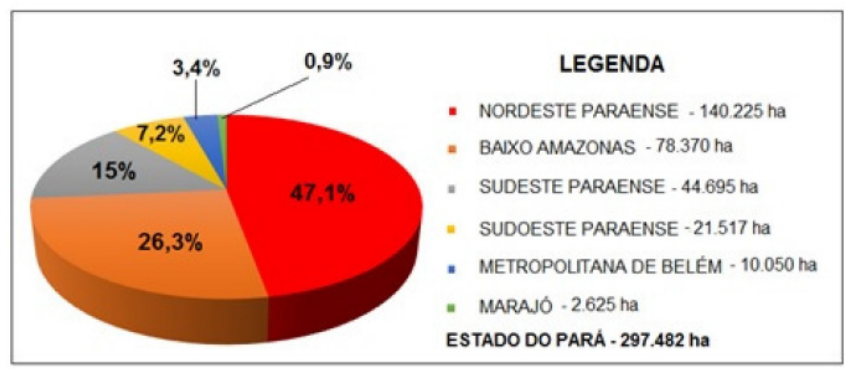

Figura 3 - Área plantada de mandioca em hectares por mesorregião no Estado do Pará, considerando o ano de 2010.

Fonte: Elaborado pelos autores a partir dos dados do IBGE

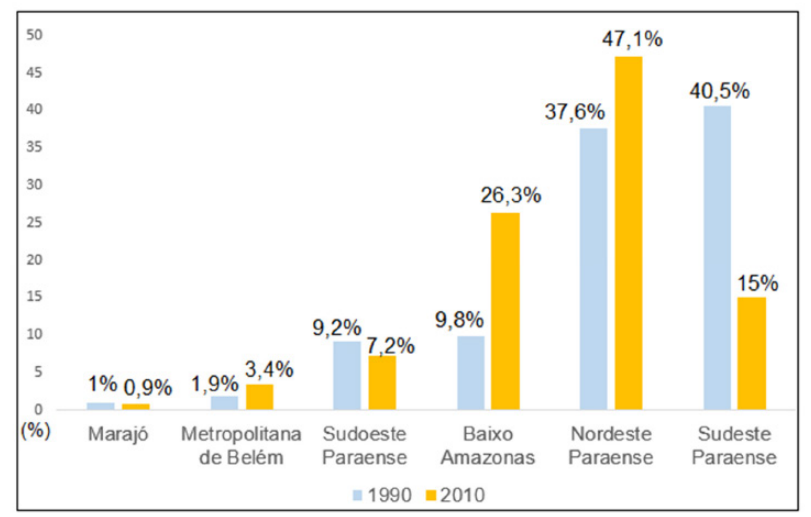

Figura 4. Participação por mesorregião no Estado do Pará na área plantada de mandioca em 1990 e 2010.

Fonte: Elaborado pelos autores a partir dos dados do IBGE

Essa situação pode ser constatada a partir de dados do IBGE 2010 (IBGE, 2015c), segundo o qual, apesar de o Pará ter a maior produção nacional de mandioca, possui uma produtividade de apenas $15.489 \mathrm{Kg} / \mathrm{ha}$, colocando-o em $12^{\circ}$ entre as unidades da federação, muito abaixo da produtivida- 
de de $23.302 \mathrm{Kg} / \mathrm{ha}$ do Paraná $\left(1^{\circ}\right)$ ou de $22.372 \mathrm{Kg} / \mathrm{ha}$ de São Paulo $\left(2^{\circ}\right)$, que têm os melhores desempenhos do país. A produtividade de mandioca no Estado do Pará denota a baixa inserção de tecnologias na cadeia produtiva desse produto quando comparado com o Estado do Paraná, com plantio e colheita mecanizada, com alta produtividade da terra e mão de obra efetuada por médios e grandes produtores.

No que tange à produção de mandioca no Pará, em 1990 a mesma correspondia a 2.894.635t, passando em 2010 para 4.596.083 t, o que representou um aumento de 58,7\% neste período. Tal dinâmica da produção de mandioca no Estado pode ser observada espacialmente na Figura 6.
No período compreendido entre 1995 e 2005, é visível a dispersão da produção de mandioca em diversas microrregiões, como Tomé-Açu, Santarém, Óbidos, Castanhal e Guamá, em decorrência da significativa ampliação da área plantada desta cultura. Por outro lado, também é perceptível a estagnação ou a baixa produção de mandioca nas microrregiões do Sudeste Paraense, Sudoeste Paraense, Marajó e Metropolitana de Belém. Este comportamento está associado a escassez de mão de obra, migração, expansão da pecuária, reflorestamento e agricultura mecanizada de grãos.

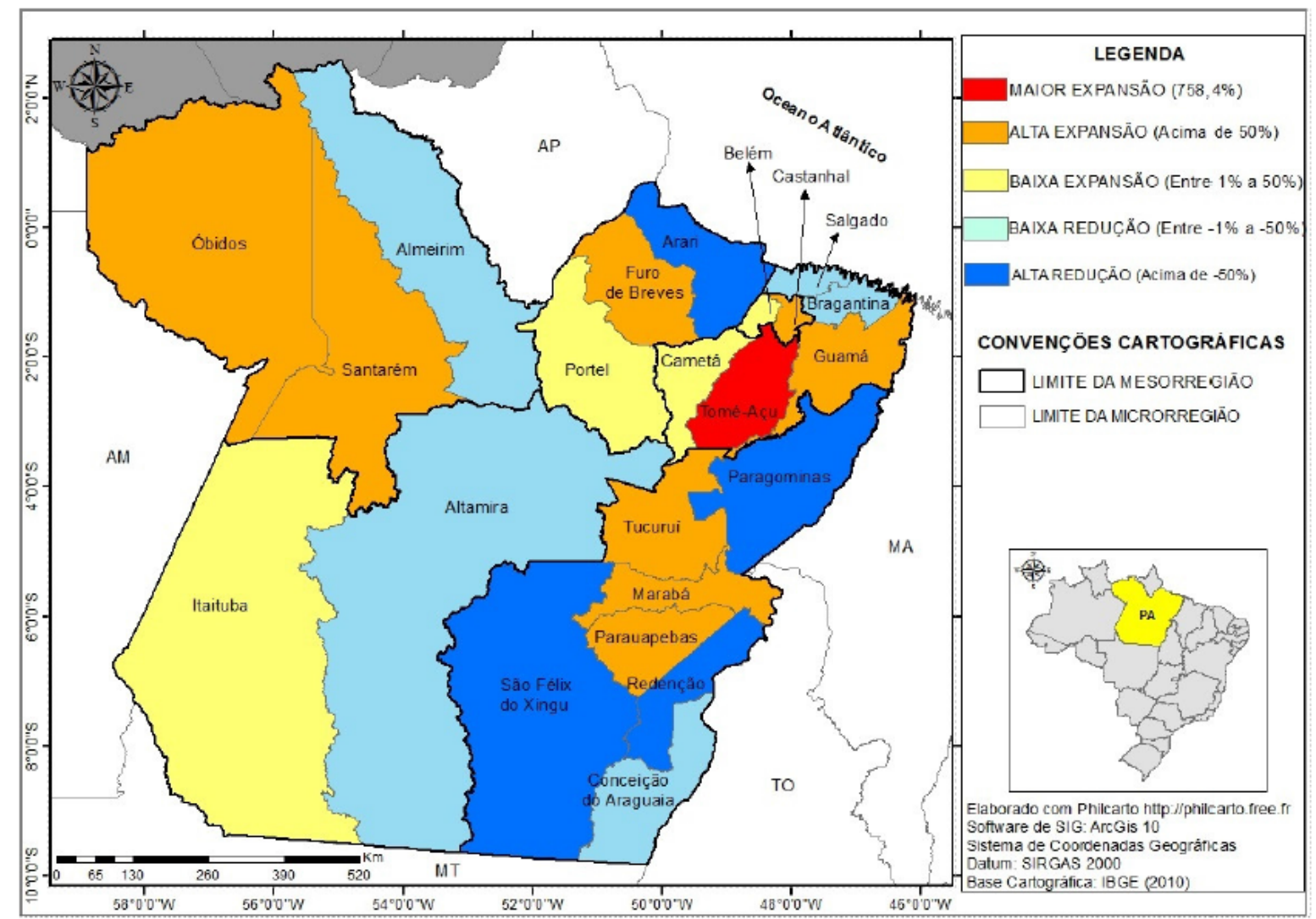

Figura 5 - Variação percentual da área plantada de mandioca entre 1990 e 2010 nas microrregiões do Estado do Pará. Fonte: Elaborado pelos autores

Como pode ser visualizado na Figura 6, a produção de mandioca em 1990 estava concentrada em microrregiões do Nordeste Paraense e do Sudeste Paraense, com destaque para Paragominas, Guamá, Bragantina, Redenção e Altamira, cuja produção oscilava entre 235.000 e 711.000 t/ ano. Neste contexto, a microrregião de Paragominas era líder, com uma produção de 711.000 t, o que correspondia a 24,5\% do Pará (IBGE, 2015a), enquanto as demais regiões possuíam baixíssimas participações na composição do estado.
Segundo Alves e Modesto Junior (2012), outra razão que poderia explicar a dificuldade de modernização da produção pela pequena produção no Pará é a reduzida oferta de tecnologia e assistência técnica aos produtores, a falta de mão de obra e lenha e os problemas climáticos, o que ocasionaria a redução no acesso ao financiamento de suas atividades agrícolas. 


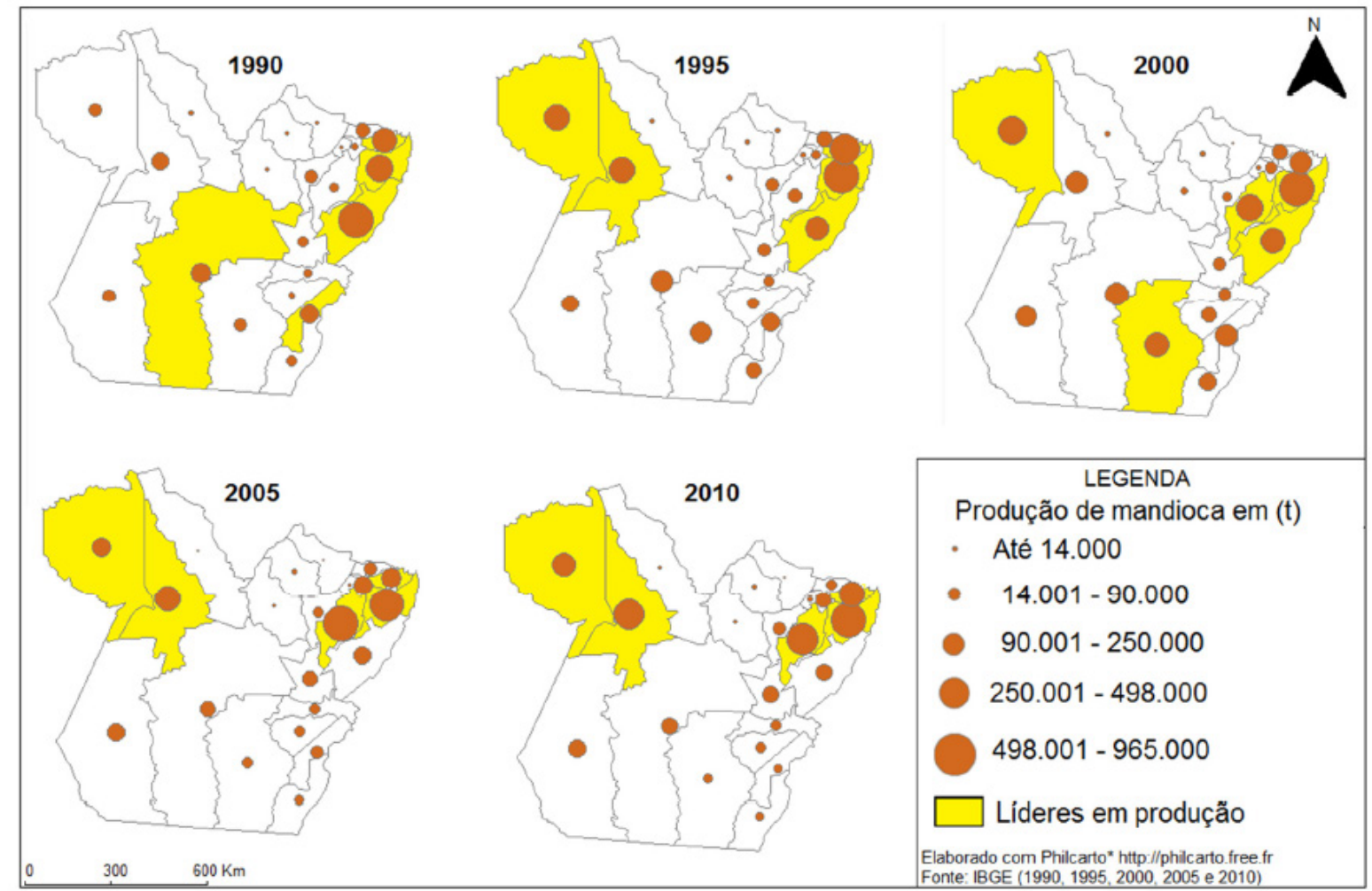

Figura 6 - Produção de mandioca em toneladas nas microrregiões do Estado do Pará em 1990, 1995, 2000, 2005 e 2010.

Fonte: Elaborado pelos autores a partir dos dados do IBGE

Além disso, o uso do fogo como a opção mais comum para o preparo da terra destinada à pequena agricultura na Amazônia representa uma grande ameaça ao sistema de produção da mandioca, pois dentre outros problemas, impacta profundamente o equilíbrio dos ciclos dos nutrientes do solo, comprometendo dessa maneira a produção agrícola em longo prazo.

Assim, essas são algumas das razões que explicam a estagnação ou redução da produção de mandioca em algumas microrregiões paraenses, tanto naqueles municípios com grande dinamismo quanto nos municípios com reduzido dinamismo da sua agricultura. Nesse caso, a adoção de técnicas agrícolas adequadas com baixo custo associado é essencial para expandir a produção de mandioca no Pará.

Considerando o último ano de análise (2010), foi possível perceber que as microrregiões de Tomé-Açu, Guamá, Santarém e Óbidos se destacaram na produção de mandioca no Estado, ultrapassando individualmente valores de 200.000 toneladas por ano.
Isto contribuiu para que o Nordeste Paraense e o Baixo Amazonas se consolidassem como líderes de produção desse produto no universo das mesorregiões do Estado (Figura 7). Tais mesorregiões também experimentaram os maiores acréscimos nos últimos 20 anos (Figura 8), visto de maneira análoga ao observado anteriormente para a variável área plantada.

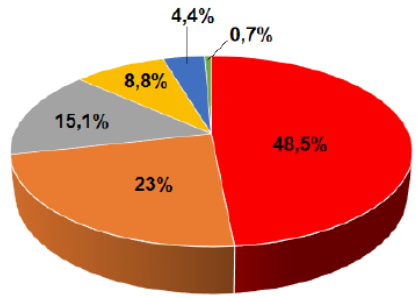

\footnotetext{
LEGENDA

- NORDESTE PARAENSE - 2.228.013t

- BaIXo AMAZONAS - $1.057 .270 \mathrm{t}$

- SUDESTE PARAENSE - $691.950 \mathrm{t}$

- Sudoeste paraense - $404.600 \mathrm{t}$

- Metropoltana de belém - $184.150 t$

- MARAJo - 30.100 t

ESTADO DO PARA $-4.596 .083 \mathrm{t}$
}

Figura 7 - Produção de mandioca em toneladas por mesorregião no Estado do Pará considerando o ano de 2010.

Fonte: Elaborado pelos autores a partir dos dados do IBGE

É visível que o Nordeste Paraense e o Baixo Amazonas tiveram as maiores variações positivas na produção de mandioca do Estado do Pará, com acréscimo de 13,6\% e 13,3\% respectivamente. Por outro lado, o Sudeste Paraense e o Sudoeste Paraense tiveram reduções significativas de 26,5\% 
e $2,9 \%$, respectivamente, enquanto as demais mesorregiões demonstraram ter um comportamento não representativo.

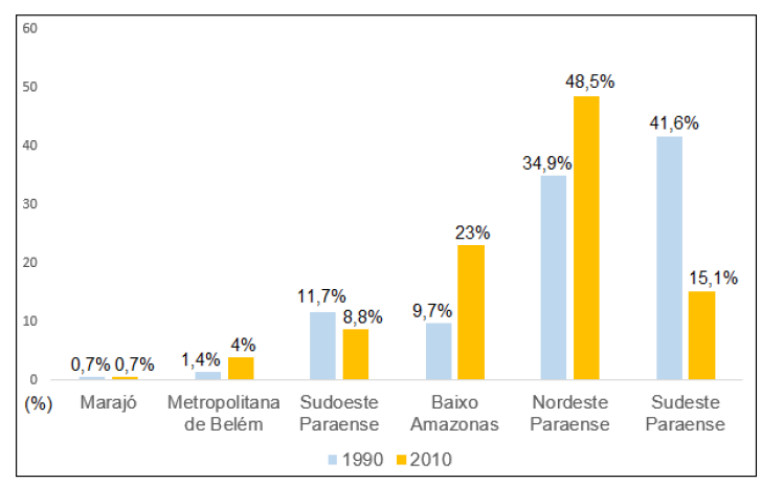

Figura 8 - Participação por mesorregião do Estado do Pará na produção de mandioca em 1990 e 2010.

Fonte: Elaborado pelos autores

Em outra análise espacial, agora considerando o mapa coroplético correspondente à Figura 9, observa-se que oito microrregiões $(36 \%)$ registraram um decréscimo na produção de mandioca durante o período de análise, sendo três delas classificadas como de alta redução e cinco como de baixa redução. Conforme Modesto Júnior e Alves (2014), a redução da produção de mandioca reflete diretamente na oferta da farinha de mesa no mercado, pois é o principal produto extraído dessa cultura no Pará.
Em situação oposta, a microrregião de Tomé-Açu teve o melhor desempenho do Estado nos últimos 20 anos, pois houve um acréscimo de $1.119 \%$ na produção de mandioca, passando de 53.600 t em 1990 para 691.200 t em 2010, o que favorece a exportação desse produto para grandes mercados consumidores, como a Região Metropolitana de Belém e outros centros urbanos regionais com alta demanda por farinha de mesa.

Nos últimos vinte anos, o aumento da produção de mandioca no Estado do Pará tem sido acompanhado pela ampliação da área plantada na maioria das microrregiões (64\% do total), sendo este processo mais intenso em Tomé-Açu (1.119\%), Castanhal (421\%), Óbidos (302\%), Santarém (284\%), Parauapebas (219\%) e Guamá (120\%), conforme pode ser observado na Figura 9. Tal comportamento é benéfico em termos socioeconômicos pela reconhecida importância dessa cultura para a dieta alimentar da população paraense (ALVES e MODESTO JÚNIOR, 2012).

Em outro extremo, ainda considerando a Figura 9, observa-se que as microrregiões de Paragominas, Redenção, São Félix do Xingu, Conceição do Araguaia e Arari foram enquadradas na categoria de alta redução (Acima de -50\%) das variáveis área plantada e produção de mandioca.

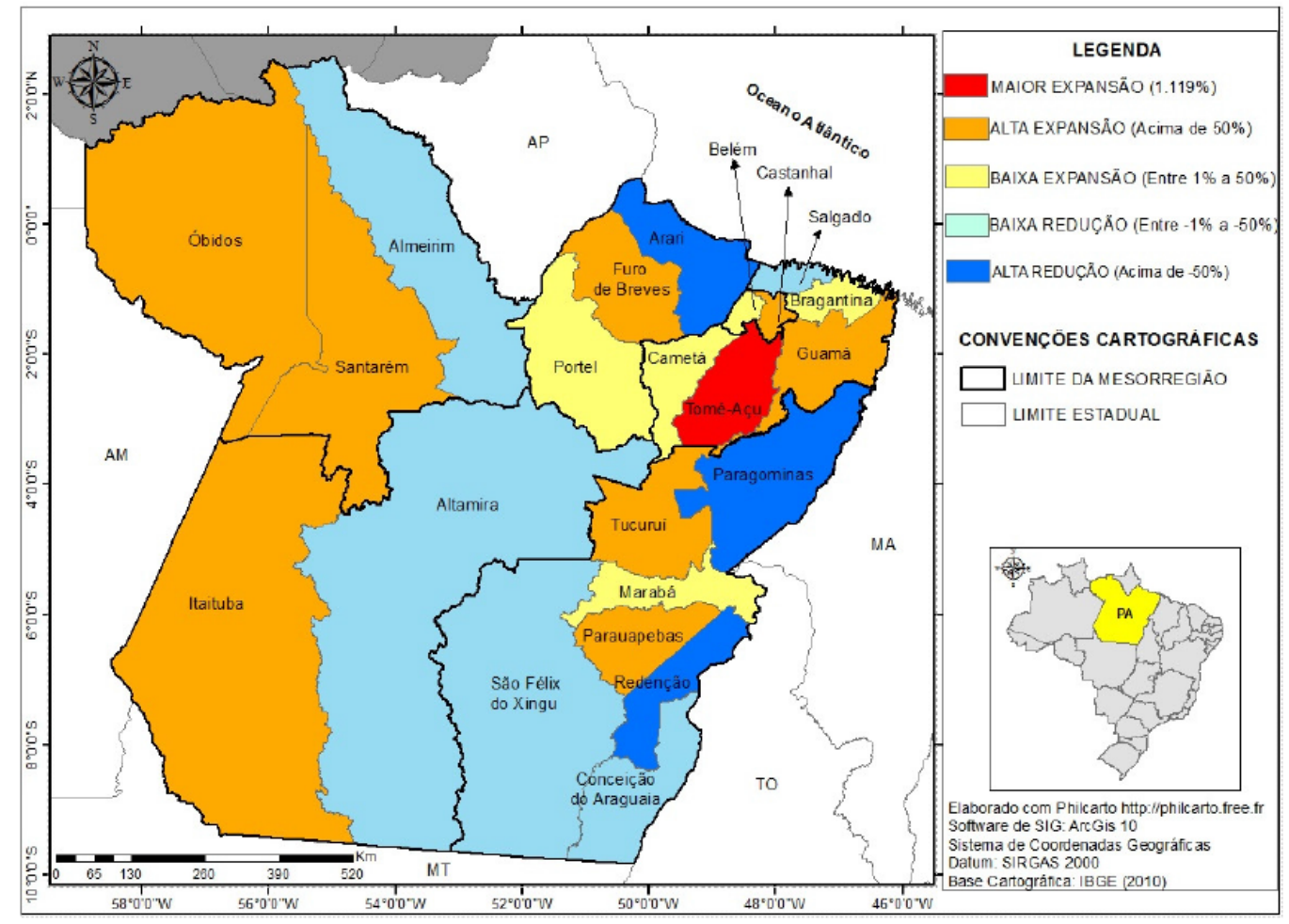

Figura 9 - Comportamento da produção de mandioca nas microrregiões entre 1990 e 2010, nas microrregiões do Estado do Pará. Fonte: Elaborado pelos autores 
Em uma análise sumária, foi possível perceber uma correlação direta entre o comportamento da área plantada e da produção em uma parte significativa do Estado (Figura 10), com exceção da microrregião Bragantina, onde a redução da área plantada foi acompanhada do crescimento na produção de mandioca, o que denota ganho substancial na produtividade. ainda que, em algumas áreas específicas dessas mesorregiões, mais recentemente, vem crescendo o cultivo mecanizado de soja e milho.

A partir de dados do Censo Agropecuário 2006 (IBGE, 2015b), observou-se que 68,6\% da produção de mandioca no Estado do Pará é proveniente de propriedades com até 100 hectares, sendo estas responsáveis por mais da metade da área colhida naquele ano $(51,9 \%)$.

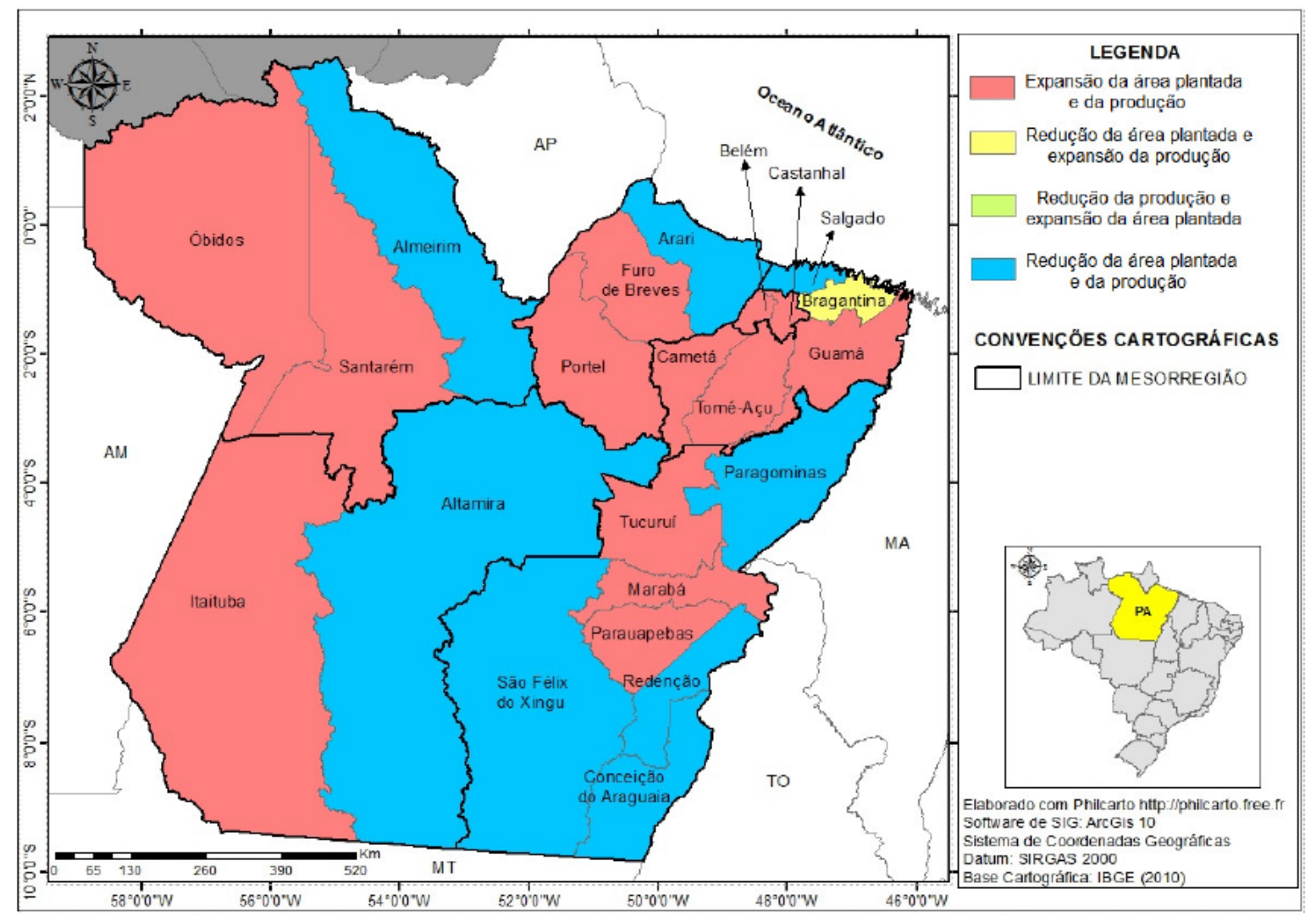

Figura 10 - Comportamento da correlação entre área plantada e produção de mandioca após 20 anos nas microrregiões do Estado do Pará.

Fonte: Elaborado pelos autores

O mapa representado na Figura 10 também evidencia que há basicamente duas zonas distintas no cultivo de mandioca no Estado do Pará, considerando as variáveis área plantada e produção. A primeira, onde houve expansão das duas variáveis consideradas, engloba a mesorregião Metropolitana de Belém, grande parte do Nordeste Paraense, Marajó e Baixo Amazonas, associadas a áreas de ocupação mais antiga, já consolidadas, e com forte tradição no cultivo e consumo desta cultura.

Em oposição, é visível a perda da importância do cultivo da mandioca em partes significativas das mesorregiões Sudoeste Paraense e Sudeste Paraense, regiões com colonização mais recente, de fronteira agrícola, onde as atividades ligadas à pecuária assumem maior destaque. Vale ressaltar
Tais dados confirmam a estreita associação desta atividade produtiva com a pequena produção, pois, como cultura de grande rusticidade, tolera baixo nível tecnológico, aproveitando-se apenas de conhecimento popular para o seu cultivo. Tal afirmativa é corroborada por Mattos e Cardoso (2013), que reafirmam sua importância social, como a principal atividade geradora de trabalho no meio rural, contribuindo para a fixação do homem no campo.

A produção de produtos da raiz da mandioca, como a farinha de mesa e a farinha de tapioca, apresenta excelente potencial para organização de pequenos negócios rurais na Amazônia, porém, na maioria das vezes, tais produtos são ainda processados por pequenos empreendimentos informais (ALVES e MODESTO JÚNIOR, 2012). Grande parte 
dos produtos de mandioca produzidos no Pará é oriunda de locais com infraestrutura rústica, como "retiros" ou "casas de farinha" de âmbito familiar, sem o uso dos protocolos desejados no preparo de alimentos. Dessa forma, faz-se necessário reverter este quadro para que os seus produtos possam alcançar mercados mais exigentes no país.

Considerando a análise da concentração e geografia do cultivo de mandioca no Estado do Pará, entende-se que os investimentos neste agronegócio devem ser priorizados principalmente para as microrregiões de Tomé-Açu, Guamá, Bragantina, Óbidos e Santarém (Figura 11). Isto se deve ao fato que, juntas, tais regiões são detentoras de $67 \%$ da produção e 67,6\% da área plantada desta cultura no Estado (IBGE, 2010), além de grande parte das mesmas terem experimentado desempenhos agrícolas positivos nos últimos 20 anos. próximo de grandes mercados consumidores, como a Região Metropolitana de Belém e as cidades de Barcarena, Castanhal, Paragominas e Bragança. Já o segundo polo está localizado no Baixo Amazonas (Microrregião de Santarém e Óbidos), nas imediações das cidades de Santarém, Óbidos e Oriximiná.

O lançamento do Programa de Produção Sustentável de Palma de Óleo no Brasil pelo Presidente Luís Inácio Lula da Silva (2003-2011), em Tomé-Açu, em 6 de maio de 2010, promoveu uma grande redução da área plantada e da produção de mandioca ao longo dos últimos anos na principal microrregião produtora de mandioca, Tomé-Açu, conforme as figuras 12 e 13. Esta substituição de área, associada à seca no Nordeste brasileiro, promoveu uma súbita elevação no preço da farinha de mandioca em 2013, afetando os consumidores paraenses.

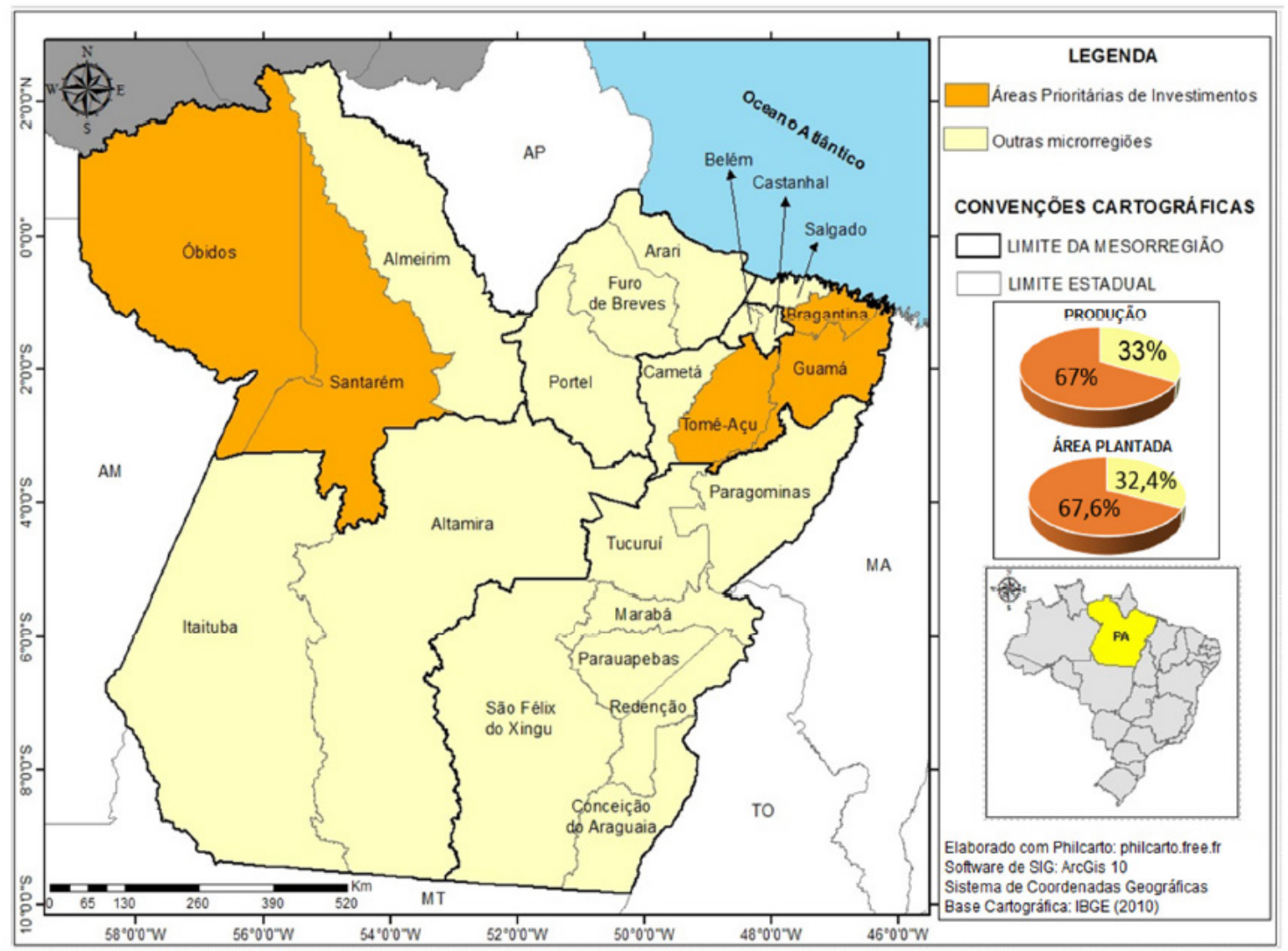

Figura 11 - Áreas prioritárias para investimento no agronegócio da mandioca no Estado do Pará. Fonte: Elaborado pelos autores

Em outra análise, é possível afirmar que no Estado do Pará há dois principais polos de maior volume na produção e na comercialização de mandioca. O primeiro está localizado no Nordeste Paraense (Microrregião da Bragantina, Guamá e Tomé-Açu),
Contudo, esta queda de produção da mandioca não ocorreu apenas nas áreas onde ocorreu a expansão do dendezeiro, mas também em outras áreas, cujas causas estão associadas, a escassez de mão de obra, programas de transferências governamentais, falta de água, entre outros. Há várias 
políticas que precisam ser desencadeadas para auxiliar esses produtores, tais como casas de farinha comunitárias, mecanização parcial no processo de fabricação da farinha, tratores e implementos agrícolas para atendimento coletivo, fertilizantes e calcário para aumentar a produtividade, melhoria da qualidade e, sobretudo, infraestrutura social.

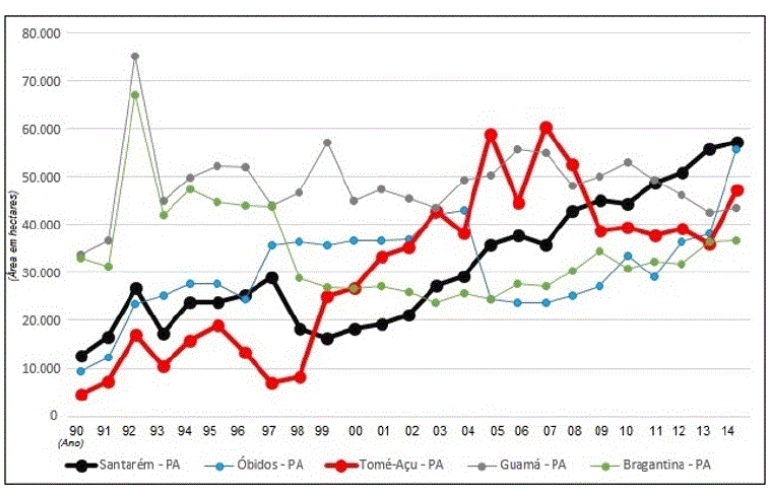

Figura 12. Área plantada de mandioca nas microrregiões prioritárias do Pará no período de 1990 a 2014.

Fonte: Elaborado pelos autores a partir dos dados do IBGE

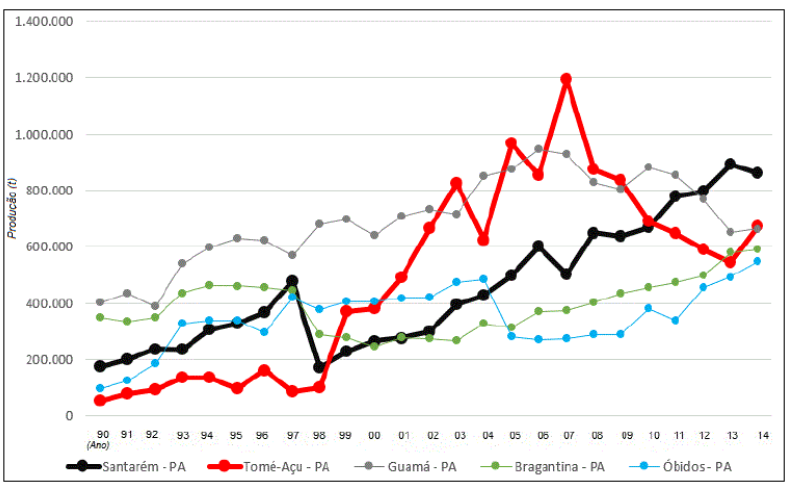

Figura 13. Produção de mandioca nas microrregiões prioritárias do Pará no período de 1990 a 2014

Fonte: Elaborado pelos autores a partir dos dados do IBGE

Listamos abaixo, sem preocupação com escala de prioridade ou de importância, algumas ações que precisariam ser desencadeadas:

- Baixo nível de organização dos produtores - a maioria das associações de agricultores existentes é formada com objetivo de se beneficiar de programas governamentais. Existe uma carência geral de organização que ajude, oriente e facilite o planejamento e a profissionalização da produção, a aquisição de insumos e implementos e a comercialização de produtos derivados da mandioca de modo coletivo, para reduzir custo e agregar valor à produção.

- Falta de política pública de incentivo à produção em escala de agronegócio, pois mais de $90 \%$ da produção de mandioca vem da pequena produção com baixo nível tec- nológico, baixa produtividade, falta de padronização, falta de qualidade do produto e aumento de custos com logística.

- Uma das grandes limitações dos atuais produtores de farinha no Nordeste Paraense refere-se à busca de lenha, que chega a participar entre 10 e $15 \%$ do custo de produção de farinha. As capoeiras do Nordeste Paraense, depois de dezenas de anos de queimadas e derrubadas sucessivas já não conseguem produzir lenha suficiente para aquecer os fornos das casas de farinha. Isso obriga a busca de lenha ou de resíduos de serrarias em locais distantes. Os produtores de mandioca necessitam urgentemente ser estimulados a plantar árvores de rápido crescimento recomendadas pela pesquisa para assegurar estoque de lenha para produzirem farinha.

\section{CONSIDERAÇÕES FINAIS}

Os resultados da pesquisa mostraram a eficiência do uso de mapas temáticos na representação espacial de distribuição, desigualdade e evolução dos componentes do cultivo de mandioca no Estado do Pará, ao conseguir demonstrar a sua dinâmica espaço-temporal, salientando os contrastes inter-regionais através de técnicas de mapeamento disponíveis pelo software livre Philcarto.

O Nordeste Paraense e o Baixo Amazonas concentram as maiores áreas cultiváveis e produção de mandioca do Estado do Pará, assim como também registraram as mais altas expansões desta atividade nos últimos anos, impulsionados principalmente pelas microrregiões de Tomé-Açu, Guamá, Óbidos e Santarém, onde é preciso intensificar investimentos financeiros para o fortalecimento do agronegócio da mandioca com o intuito de pequenos produtores conseguirem comercializar para mercados mais exigente do país. O Sudeste e Sudoeste Paraense registraram reduções significativas na produção de mandioca nos últimos anos em decorrência do avanço da atividade pecuária e da agricultura mecanizada.

Este estudo vem confirmar a dinâmica do cultivo da mandioca no Estado do Pará, no qual novas transformações estão ocorrendo. No período de 2000 a 2010, com o avanço do cultivo de dendezeiro para alguns municípios onde ocorreu esta expansão, a safra de mandioca foi seriamente afetada. Além da competição por área ocorre também a realocação de mão de obra, atraída com as vantagens de um emprego com carteira assinada. Ressalta-se que a redução de área ocorreu também para municípios que não tiveram nenhuma influência com o plantio de dendezeiros.

\section{REFERÊNCIAS BIBLIOGRÁFICAS}

ALVES, R. N. B; MODESTO JÚNIOR, M. de S. Roça 
sem fogo e trio da produtividade da mandioca. Revista Inclusão Social. Brasília. v.6. n.2. 77-83. jan/jun.2012. Disponível em: http://revista.ibict.br/inclusao/index.php/ inclusao/article/view/254. Acesso em 18/06/2015.

BERTIN, J. A neográfica e o tratamento da informação. Curitiba: Editora da UFPR, 1986. 273 p.

ESRI. ArcGIS: a complete integrated system. Disponível em <http://www.esri.com/software/arcgis/>. Acesso em: 06/08/2015.

GIRARDI, E.P. Proposição teórico-metodológica de uma cartografia geográfica crítica e a sua aplicação no desenvolvimento do atlas da questão agrária brasileira. Tese (Doutorado em Geografia) - Universidade Estadual Paulista/ Faculdade de Ciências e Tecnologias, Presidente Prudente, SP. 2008.

HOMMA, A.K.O. Sinergias de mudanças para uma nova agricultura na Amazônia. In: VIEIRA, I. C. G.; JARDIM, M. A. G.; ROCHA, E. J. P. (Org.). Amazônia em tempo: estudos climáticos e socioambientais. Belém: Universidade Federal do Pará; Museu Paraense Emílio Goeldi; Embrapa Amazônia Oriental, 2015. p. 51-80.

IBGE. Censo agropecuário 1990, 1995, 2000, 2005 e 2010. Disponível em <http://www.sidra.ibge.gov.br/bda/ tabela/listabl.asp? $\mathrm{z}=\mathrm{t} \& \mathrm{o}=11 \& \mathrm{i}=\mathrm{P} \& \mathrm{c}=1612>$. Acesso em 20/05/2015a.

Censo agropecuário 2006. Disponível em: <http://www.sidra.ibge.gov.br/bda/tabela/listabl. asp? $\mathrm{z}=\mathrm{t} \& \mathrm{o}=11 \& \mathrm{i}=\mathrm{P} \& \mathrm{c}=1244>$. Acesso em 20/04/2015b.

Censo agropecuário 2010. Disponível em: http://www.sidra.ibge.gov.br/bda/tabela/listabl. asp? $z=t \& o=11 \& i=P \& c=1612$. Acesso em 20/04/2015c.

MARTINELLI, M. Mapas da geografia e cartografia temática. São Paulo: Contexto, 2011. $3^{\mathrm{a}}$ Ed.

MATTOS, P. L. P.; CARDOSO, E. M. R. Cultivo da mandioca para o Estado do Pará. Disponível em: <http:/ / sistemasdeproducao.cnptia.embrapa.br/FontesHTML/ Mandioca/mandioca_para/mercado.htm $>$. Acesso em 15/03/2013.

MODESTOJÚNIOR, M; ALVES, R. N. B. Rentabilidades de farinhas no estado do Pará. In: EMBRAPA. Cultura da Mandioca (Apostila). Belém/PA. Ed: Embrapa Amazônia Oriental. $1^{\circ} \mathrm{Ed}$. 2014. p.139-152. Disponível em http:/ / ainfo.cnptia.embrapa.br/digital/bitstream/item/112346/1/ Apostila-Mandioca.pdf. Acesso em 26/07/2015.

PHILCARTO. [Software]. Disponível em: http://philcarto.free.fr/Inscriptions.html>. Acesso em 20/05/2014.

SILVA, A. Manejo e conservação do solo. In: EMBRAPA. Cultura da Mandioca (Apostila). Belém/PA. Ed: Embrapa Amazônia Oriental. $1^{\circ} \mathrm{Ed}$. 2014. p. 29-44. Disponível em http://ainfo.cnptia.embrapa.br/digital/bitstream/item/112346/1/Apostila-Mandioca.pdf. Acesso em 25/07/2015.

WANIEZ, P. Les donnés et Le territoir au Brésil. In: Sociedade, Meio Ambiente e Território no Brasil. Paris: IRD, 2002.

Correspondência dos autores:

\author{
Luiz Henrique Almeida Gusmão \\ e-mail: henrique.ufpa@hotmail.com \\ Alfredo Kingo Oyama Homma \\ e-mail: alfredo.homma@embrapa.br \\ Orlando dos Santos Watrin \\ e-mail: orlando.watrin@embrapa.br
}

Artigo recebido em: 14/01/2016

Revisado pelos autores em: 06/07/2016

Aceito para publicação em: 20/08/2016 